\title{
Voltammetric determination of human papillomavirus 16 DNA by using interdigitated electrodes modified with titanium dioxide nanoparticles
}

\begin{abstract}
A gene sensor for rapid detection of the Human Papillomavirus 16 (HPV 16) which is associated with the appearance of cervical cancer was developed. The assay is based on voltammetric determination of HPV 16 DNA by using interdigitated electrodes modified with titanium dioxide nanoparticles. Titanium dioxide nanoparticles (NPs) were used to modify a semiconductor-based interdigitated electrode (IDE). The surface of the NPs was then functionalized with a commercial 24-mer oligomer DNA probe for HPV 16 that was modified at the 5' end with a carboxyl group. If the probe interacts with the HPV 16 ssDNA, the current, best measured at a working voltage of $1.0 \mathrm{~V}$, increases. The gene sensor has has a $\sim 0.1 \mathrm{fM}$ limit of detection which is comparable to other sensors. The dielectric voltammetry analysis was carried out from $0 \mathrm{~V}$ to $1 \mathrm{~V}$. The electrochemical sensitivity of the IDE is $2.5 \times 10^{-5}$ $\mu \mathrm{A} \cdot \mu \mathrm{M}^{-1} \cdot \mathrm{cm}^{-2}$. Graphical abstract Schematic of an interdigitated electrode (IDE) modified with titanium dioxide nanoparticles for voltammetric determination of HPV 16 DNA by using an appropriate DNA probe.
\end{abstract}

Keyword: Voltammetric assay; Human Papillomavirus; Interdigitated electrodes; DNA; Titanium dioxide 